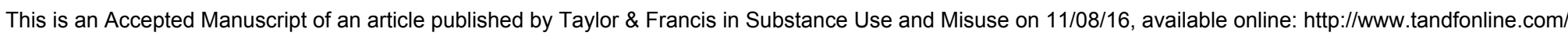
doi/full/10.1080/10826084.2016.1197937 


\section{ESTIMATES OF THE ABSOLUTE AND RELATIVE STRENGTHS OF DIVERSE ALCOHOLIC DRINKS}

\section{BY YOUNG PEOPLE}

Stephanie Walker, Suzanne Higgs and Philip Terry ${ }^{1}$.

School of Psychology, University of Birmingham, Edgbaston, Birmingham B15 2TT, United Kingdom; ${ }^{1}$ Department of Psychology, Kingston University, Penrhyn Road, Kingston-uponThames, Surrey KT1 2EE, United Kingdom

Correspondence to Philip Terry at: Department of Psychology, Kingston University, Penrhyn Road, Kingston-upon-Thames, Surrey KT1 2EE, UK;

Email: p.terry@kingston.ac.uk; Tel: +44(0)2084177161.

Running Title: Estimates of alcohol content

Declaration of Interest: The authors report no conflicts of interest. The authors alone are responsible for the content and writing of the paper. 


\section{ABSTRACT}

Background: Evidence suggests that college students are often unclear about how much alcohol is present in different drinks. Objectives: To evaluate the abilities of students to estimate the alcohol contents of drinks, both in relative and absolute terms, and to examine how alcohol strength informs behavior. Methods: For 10 popular drinks that varied by alcohol content, beverage and volume, 209 UK university students rank-ordered the drinks according to total alcohol content and then estimated, for each drink, the number of UK "units" of alcohol contained and its percentage alcohol-by-volume (\%ABV). Participants also reported the importance of drink strength as a factor in drink choice, and its influence in different scenarios. Results: There was low but significant concordance between participants' rank-orderings of drinks by strength, and the correlation of mean ranks with correct ranks was also significant. However, their explicit estimates of the numbers of "units" in the drinks, and their \%ABV values, often diverged dramatically from actual values. Participants tended to overestimate the unit contents of spirit-based drinks but underestimated the unit contents of beers and wine; women were consistently less accurate than men, typically making greater underestimates for commonly-consumed drinks. Over one-third of the sample reported that strength influenced drink choice, but its importance ranked below flavour and cost; drink strength might contribute to drink choice depending on the drinking situation. Conclusion/Importance: Young drinkers (women especially) have a poor awareness of the alcohol contents of different drinks, particularly wines and beers, but they make better judgments of relative strength.

Keywords: Drink labelling; College drinking; Alcohol strength; Alcohol content; Intoxication 


\section{INTRODUCTION}

In order to avoid drinking harmful amounts of alcohol on a particular drinking occasion, the volume of a beverage and its alcohol content need to be taken into account. However, these characteristics can be difficult to judge, since drinks are available in a wide range of different strengths and volumes; these properties can vary not only according to drink type but also within and between drinking contexts. Thus the strength of an alcoholic drink may range from around 3\% alcohol-by-volume (\% ABV) for weak beers up to around $50 \% \mathrm{ABV}$ for some spirit-based drinks (Dufour, 1999; Ferner \& Chambers, 2001). Different brands of the same drink type may vary considerably in strength (e.g. DiLoreto et al., 2012), and even within a brand there can be a range of strengths of the same drink type (e.g. lager beers). Drink volume may seem a more reliable cue, but the variety of quantities available for purchase or self-administered by drinkers (e.g. Kerr, Greenfield, Tujague, \& Brown, 2005) can also create confusion in terms of self-monitoring alcohol intake.

In the UK there are two conventional ways of providing information about the amount of alcohol in a particular beverage: \% ABV and "units" of alcohol. The biggest problem with the $\% A B V$ measure is that it does not take into account the volume of the drink: although the total amount of alcohol in a drink can be calculated by knowing the drink volume and its \% $A B V$, it is not an easy calculation for most people (Ferner \& Chambers, 2001; Kerr \& Stockwell, 2012). Indeed, evidence shows that people are poor at estimating the alcohol content of a drink even when they know its \% ABV and its volume (Higgs, Stafford, Attwood, Walker, \& Terry, 2008; Stockwell, 1993; Stockwell \& Stirling, 1989; Webster-Harrison Barton, Sanders, Anderson, \& Dobbs, 2002). Participants were particularly inaccurate when 
estimating the alcohol contents of drinks with high or low \% ABV values (Stockwell \& Stirling, 1989). Additionally, Sastre, Mullet, \& Sorum (2000) found that, even for equivalent drink volumes, participants incorrectly made a much bigger distinction between the intoxicating effects of beer ( $4.5 \% \mathrm{ABV})$ versus water $(0 \% \mathrm{ABV})$ than between the effects of beer and wine (12\% ABV) or between wine and port ( $20 \% \mathrm{ABV})$.

In part to address the difficulties associated with merging concentration and volume information, various countries have adopted "standard drink" measures that apply across beverage types and volumes (Kerr \& Stockwell, 2012). However, the amounts of alcohol present in a "standard drink" can vary widely between countries: for example, $10 \mathrm{~g}$ in Australia and Spain, approximately $14 \mathrm{~g}$ in the US, and $19.75 \mathrm{~g}$ in Japan (Dufour, 1999; Furtwaengler \& DeVisser, 2013; Kerr \& Stockwell, 2012). In the UK, alcohol content is defined by the number of "units" of alcohol contained in a drink; one unit of alcohol corresponds to $7.9 \mathrm{~g}(10 \mathrm{ml})$ of alcohol. Results from the Office for National Statistics Omnibus Survey (2010) showed that $90 \%$ of all UK adults in 2009 had heard of unit measurements for alcohol content. However, this awareness may not translate into practical application: in the same survey, only $13 \%$ reported monitoring their own intake by units. Gill \& O'May (2007a) also found that only $14 \%$ of newly-matriculated, Scottish female students claimed to use the unit system to monitor their drinking, and only $54 \%$ recalled the recommended daily unit intake guidelines for women. Similarly, De Visser \& Birch (2012) reported that UK university students showed a poor understanding of the "unit" measurement and consistently underestimated the alcohol contents of common drinks; moreover they did not consider government intake guidelines to be useful. Boniface, Kneale, \& Shelton (2013) also reported widespread inaccuracies in estimating the unit 
contents of self-poured drinks among a broader adult (non-student) sample. Perhaps more worryingly, a survey of 445 medical doctors in the UK county of Yorkshire in 2009 found that only $18 \%$ were "fully conversant" with the unit system, even though $79 \%$ claimed to be familiar with it, and only $68 \%$ correctly reported current medical guidelines for unit intake per week (Das, Corrado, Kyerematen, Smithson, \& West (2009). The unit system probably works best for drinks in bottles or served in licensed premises where standard volumes are used (this is less common in the US). It may be misleading when people are pouring their own drinks if they do not account for the discrepancy between 'standard' measures (e.g. a $25 \mathrm{ml}$ shot of spirits) and their own. Numerous studies in several countries have shown that people pour much more than the standard volumes in free-pour paradigms (Boniface Kneale, \& Shelton, 2013; De Visser \& Birch, 2012; Gill \& Donaghy, 2004; Gill \& O'May, 2007b; Gill, Donaghy, Guise, \& Warner, 2007; Lemmens, 1994; White, Kraus, McCracken, \& Swartzwelder, 2003; White et al., 2005). In studies by Gill and colleagues (Gill \& Donaghy, 2004; Gill \& O'May, 2007b; Gill, Donaghy, Guise, \& Warner, 2007), volumes poured by participants were approximately double the size of standard bar measures for wine and spirits. However, volume estimation can be improved through practice or experience (Gill \& O’May, 2007b; Wansink \& Van Ittersum, 2005).

The aim of the present study was to investigate young people's knowledge of drink strengths and how such knowledge might influence drink choice. Unlike previous studies, we examined students' estimates of the alcohol contents of drinks that were known to be popular amongst the cohort, and the drink types given varied in both \% ABV and numbers of standard measures. Students are a population of interest because of long-standing concerns over levels of harmful drinking in universities and colleges (e.g. Bewick et al., 2008; Craigs, 
Bewick, Gill, O’Maya, \& Radley, 2012; Dawson, Grant, Stinson, \& Chou, 2004; Heather et al., 2011; Karam, Kypri, \& Salamoun, 2007). Sex differences in estimation accuracy were also examined in detail for the first time. To establish whether consumption of particular drinks affected estimates, participants were also asked about their drinking habits in relation to specific branded drinks. Finally, we also examined whether students report taking account of drink strength when they are choosing a drink, and how this might be influenced by situational factors. If people are able to estimate accurately the strengths of alcoholic drinks but do not use such information to direct behaviour, then it might be concluded that highlighting the strengths of alcoholic drinks, either through advertising or labeling, will not be an effective method of altering people's drinking behaviour.

\section{METHOD}

\section{Participants}

The questionnaire was administered to 209 students at the University of Birmingham (91 males and 118 females). The mean age was 20.2 years ( $S D=2.7$ years; no difference between males and females; range $18-30$ years old). Participants were recruited from across the campus as an opportunity sample by means of a stall established outside the college student union building over a 2 day period. Participants were paid $€ 2$ (approximately 3 US dollars) for taking part. Volunteers were excluded if they did not drink alcoholic beverages at all or only drank them very infrequently ( $<1$ drink/week by self-report). None of the participants was known to the researcher administering the task.

\section{Materials and Procedure}


The first phase involved three parts. Participants were always presented first with a sheet of paper listing ten different drinks that varied in terms of drink type, percentage alcohol content and volume. Nine of the ten drinks selected were the best-selling nine drinks in the main student bar on campus at the time of the study. They comprised three brands of lager beer (Stella Artois, Carling, Corona), four spirits/spirit-based drinks (Smirnoff vodka, Jack Daniels whisky; two flavoured liqueurs, Sourz and Aftershock), one wine brand (Kumala, white) and one vodka-based "alcopop" (Reef). The tenth drink, Carlsberg Special Brew, is not typically consumed by students but was included because it is widely-recognised to have a high strength relative to other beers in the UK ( $9 \% \mathrm{ABV})$ and it therefore extended the range of beer strengths represented. The stated drink volumes varied so that participants had to consider quantity as well as drink type when making judgments (drinks and quantities are shown in Table 1). The participants rank-ordered the drinks by total alcohol content from 110, with rank 1 applied to the drink with the highest alcohol content and rank 10 to the one with the lowest. Following this task, they were asked to estimate the number of UK "units" of alcohol in each drink and (separately, on a different sheet) the \% ABV for each drink; the order of presentation of the two estimate tasks was counterbalanced across participants (by alternation within sexes). Participants handed their responses to the experimenter directly after each phase so that they could not explicitly use their responses to a previous section to inform subsequent responses (or change earlier responses).

The second phase required participants to complete a questionnaire that first characterised participants' drinking habits, including what drinks they consumed (and in what quantities) in a typical week and during a typical drinking occasion; from this information, a calculation of units per week or per occasion was generated. They also reported the 3 drinks that they 
consumed most often and the frequency with which they consumed the 10 drink types given in the first phase ("Not at all", "Sometimes" or "Regularly"). To explore whether participants consider drink strength during drink selection, and how strength compares with other factors that influence choice, participants were asked to select any of 5 factors that contributed to their choice of drink: taste, cost, strength, packaging and influence of friends. Finally, participants were presented with a series of 6 common drinking scenarios for students: "having a quiet drink with lectures the next day", "getting ready before a night out", "out clubbing", "at the pub before a lecture or work", "out for dinner with their parents", and "at a house party". These scenarios have different implications in terms of the potential impacts of intoxication. Participants were asked whether they would consider drink strength when choosing a drink in each scenario, and to indicate (using tick boxes) whether they would opt for a "standard drink", a "stronger drink" or "not consider drink strength at all". Questionnaires were completed in the presence of the experimenter or a trained assistant (responses shielded), and took approximately 10 minutes to complete. The experimenter was therefore available to answer questions and ensure that the questionnaire requirements were fully understood.

\section{Analyses}

Kendall's W was calculated to test agreement between respondents on the ranking task; Spearman's rank correlation coefficient was calculated to compare estimated mean ranks with true ranks following significant concordance on Kendall's W. To examine more closely the factors that influence ranking performance, a value for Kendall's tau was calculated for each participant and used as the outcome variable in a hierarchical regression model incorporating drinking factors and gender as predictors. One sample t-tests were used to 
compare participants' estimated alcohol strengths (unit values and \%ABV) with the actual values. As there were 20 such estimates the Bonferroni correction was applied: only $p$ values $<0.0025$ were deemed significant. MANOVA was used to compare estimates by men and women across the 10 drinks. Mean error scores per category of drink (beer, spiritbased, wine) were calculated by taking the difference between estimated and actual values (\%ABV or units), expressing the outcome as a ratio relative to the actual value for each drink and participant, and then averaging over the 4 beers or 5 spirit-based drinks (there was only one exemplar of wine, so the single score was used). Finally, the sample was then split according to the 3 categories for how frequently participants consume each drink and ANOVAs were run for each of the two estimates of alcohol strength (Bonferroni corrections applied again). Numbers of participants varied from 196-209 for different analyses due to occasional failures by some participants to complete questionnaire items (missing data); numbers contributing are reported for each analysis.

\section{RESULTS}

\section{Drinking characteristics}

Males reported drinking an average of 24.7 units/week (SD = 18.3 units/week), significantly more than the females (12.7 units/week, SD = 10.3 units/week), $t(204)=5.97, p<0.01$. Males reported drinking on significantly more occasions per week $(M=3.4$ times, $S D=1.8$ times) than females ( $M=2.3$ times, $S D=1.3$ times), $t(205)=5.4, p<0.01$; and males reported consuming significantly more units per drinking occasion $(M=10.9$ units/occasion, $\mathrm{SD}=6.8$ units/occasion) than females $(\mathrm{M}=6.4$ units/occasion, $\mathrm{SD}=3.4$ units/occasion), $t(204)=6.17, p<0.01$. There was no significant difference between males and females in 
terms of the length of time that that they had been drinking at their reported drinking frequency ( $M=30.0$ months, $S D=23.6$ months $)$.

\section{Ranking task}

Agreement between the participants was low but significant in terms of their rank orderings of the drinks by total alcohol content [Kendall's $W(9)=0.26, \chi^{2}=475.18, p<0.001$ ]. There was a significant positive correlation between participants' estimated rankings of alcohol content and the true rankings $\left[r^{s}(9)=0.69, p<0.05\right]$, see Table 1 .

\section{--- TABLE 1 APPROXIMATELY HERE ---}

Individual ranking accuracies were quantified as values of Kendall's tau for each participant. Only $1 \%$ of men and $3 \%$ of women produced significant negative correlations (by tau) for rankings; the proportions producing significant positive associations were $40 \%$ and $31 \%$, respectively. Hierarchical regression was used to test for the influence of drinking factors on individual ranking accuracies. The first model incorporated factors that might be expected to predict accuracy (Step 1: units consumed per week, duration of drinking at current levels, self-reported use of strength information as a factor in choosing a drink) and the second model included gender also (no a priori prediction: Step 2). As can be seen from Table 2, both models significantly predicted ranking accuracy $(p<0.05)$, but they only accounted for around $5 \%$ of the total variance. Consumption per week and duration of consumption were significant predictors of ranking accuracy; however, neither gender nor the use of drink strength as a choice factor significantly influenced ranking accuracy. 


\section{Estimates of alcohol unit content and \%ABV}

Estimates of the numbers of units of alcohol in the drinks were significantly different from the actual values for all drinks apart from Reef. Participants significantly overestimated for Sourz, Aftershock, Smirnoff, Jack Daniels and Corona, and underestimated for Carling, Carlsberg Special Brew, Kumala white wine, and Stella Artois (see Table 2). The only sexdifference that emerged for estimation accuracy was for one item: 1 pint of Stella Artois beer: men's estimates were closer to the actual value ( $M=2.6$ units, $S D=2.1$ units) and did not differ significantly from it, in comparison's to women's estimates ( $M=2.1$ units, SD = 1.5 units) which diverged significantly from the actual value of 3 units $(p<0.001)$. Indeed, MANOVA revealed that men significantly differed from women overall in terms of their mean unit estimates ( $n=115$ women, 90 men; Pillai's Trace $F(10,194)=3.10, p=0.001)$ : for every drink where a significant difference was identified by MANOVA (items Carling, Stella Artois, Carlsberg beers; Kumala wine, Reef "alcopop"), women's estimates were consistently lower than men's, and further from the actual values (for all: $p<0.04$ ). Regression was used to test the influence of drinking variables (units consumed per week and duration of consumption at current frequency), and gender, on estimation error for the three classes of drink (beer, spirits, wine). There was no significant model fit for the beers $[F(3,194)=2.48, p$ $>0.05]$, but the deviation scores for spirits were predicted by units per week $[B=-0.02, S . E$. $B=0.008, \beta=-0.91, p<0.05]$ and gender $[B=0.539, S . E . B=0.248, \beta=0.167, p<0.05]$, model $\Delta R^{2}=0.048$; the deviation scores for wine were predicted by gender only $[B=0.163$, S.E. $B=0.054, \beta=0.229, p<0.003]$, model $\Delta R^{2}=0.056$. For the spirit drinks, the more people drank overall, the smaller the average estimation error; for both spirits and wine, male gender was associated with smaller errors for unit estimations. Estimation error sizes 
were significantly correlated between drink classes (beer vs wine: $r=0.40$; beer vs spirits: $r=$ 0.63; spirits vs wine: $r=0.33$; for all, $p<0.001$ ).

Similarly, even adopting a conservative Bonferroni correction for separate comparisons, the participants' estimates of the drinks' strengths in terms of \% ABV were significantly different from the actual values, the only exceptions being for Carlsberg Special Brew and Kumala white wine. In contrast to estimates of unit alcohol content, participants overestimated for Carling, Sourz, Reef, Corona and Stella Artois, but they underestimated for Aftershock, Smirnoff and Jack Daniels (see Table 3). Looking at the two sexes separately, a sexdifference emerged for estimation accuracy on two items: (1) Two Jack Daniels whiskeys: men's estimates were closer to the actual value ( $M=36.4 \% A B V, S D=17.1 \%)$ and did not differ significantly from it, in comparison's to women's estimates $(M=34.4 \% A B V, S D=$ $19.1 \%)$ which diverged significantly from the actual value of $40 \%$ ABV $(p<0.003)$; (2) One pint Stella Artois beer: again, men's estimates were closer to the actual value $(M=6.5 \%$ $A B V, S D=6.9 \%)$ and did not differ significantly from it, in comparison's to women's estimates ( $M=8.3 \% A B V, S D=6.8 \%)$ which diverged significantly from the actual value of 5.1\% ABV ( $<<0.001)$. MANOVA revealed that men significantly differed from women overall in terms of their mean \% ABV estimates ( $n=112$ women, 89 men; Pillai's Trace $F(10,190)=$ $1.91, p<0.05)$, but only one component drink showed a significant effect, Carling beer, for which women's estimates $(M=12.2 \% A B V, S D=11.2 \%)$ were higher than men's $(M=8.1 \%$ $A B V, S D=9.2 \%)$ and further from the actual value of $4.1 \% A B V(p<0.005)$. However, unlike for unit estimates, there was no consistent direction of difference between men and women across drink items. As for units (above), regression was then used to test the influence of drinking variables and gender on $\%$ ABV estimation error for the three classes of drink (beer, 
spirits, wine) separately. There was no significant model fit for the spirits $[F(3,192)=0.55, p$ $>0.05$ ] or for the wine $F(3,193)=0.21, p>0.05]$. For the beers, the deviation scores were predicted by gender only $[B=0.512$, S.E. $B=0.231, \beta=0.17, p<0.05]$, model $\Delta R^{2}=0.025$; male gender was associated with smaller \% ABV estimation errors for the beers overall. Estimation error sizes were strongly correlated between drink classes (beer vs wine: $r=$ 0.67; beer vs spirits: $r=0.71$; spirits vs wine: $r=0.56$; for all, $p<0.001$ ).

\section{--- TABLES 3 AND 4 APPROXIMATELY HERE ---}

\section{The relationship between drink familiarity and accuracy of estimates}

Applying a Bonferroni correction to the 20 possible ANOVAs (one ANOVA for each drink type for both measures) yielded a significance level of $p<0.0025$. There was a significant influence of drinking frequency for the drink Carling beer on estimated unit content of Carling $[F(2,203)=6.56, p=0.002]$ : post hoc tests (three possible: therefore $p<0.01$ as a conservative cut-off) indicated that only participants who drank Carling "Not at all" or "Sometimes" showed a significant divergence from the actual unit content $[t(94)=9.0, p<$ $0.01 ; \mathrm{t}(60)=8.9, \mathrm{p}<0.01$, respectively]; participants who reported drinking Carling "Regularly" did not show such an effect $[\mathrm{t}(49)=2.1, \mathrm{p}=0.04]$. There were no other differences based on frequencies of consuming any of the other drinks, and there were no significant effects of drinking familiarity for any of the drinks in terms of estimated \% ABV (for all ANOVAs, $\mathrm{p}>0.02$ ).

Reasons for choosing drinks and the influence of situation 
Respondents reported that they were most likely to consider flavour and cost when choosing a drink (see Figure 1). Less than half (39.9\%) selected strength as a reason. Chisquare test showed no association between the respondent's sex and the influence of alcohol strength on drink choice $\left[\chi^{2}(1)=0.01, p>0.05\right]$. Very few respondents thought that packaging or their friends influenced their beverage choice. The only factor that showed a significant association with sex was flavour $\left[\chi^{2}(1)=7.77, p<0.005\right]$; more men reported not being influenced by flavor (15.6\%) than women (4.3\%). For the questions relating to how drink strength might influence choice in different scenarios, participants were more likely to respond that they would choose a "stronger drink" than a "standard drink" or "not consider it at all" when at a nightclub (65.4\%) or at a house party $(57.8 \%)$ or when "getting ready to go out" $(57.3 \%)$ than in the other scenarios (see Table 4). They were more likely to choose a "standard drink" when out for a quiet drink (72.8\%) or at dinner with their parents $(71.4 \%)$ relative to other situations. The majority of respondents also opted for "not considering drink strength at all" in the pub before a lecture (50.5\%).

--- TABLE 5 AND FIGURE 1 APPROXIMATELY HERE ---

\section{DISCUSSION}

This study examined students' knowledge of the alcohol contents of popular drinks, and the factors that students claim to consider when choosing drinks. The average weekly volume of alcohol consumed by the sample (in terms of numbers of units) was similar to that reported by other studies using volunteer samples of UK students, indicating that the sample was not unusual (e.g. Craigs et al., 2012; Fadardi \& Cox, 2008). There was a significant correlation 
between the mean rank order of drink strengths provided by the sample and the true ranks of the drinks in the ranking exercise. This suggests that the participants are aware of the variation in alcohol content between drink types and can use this information in conjunction with indicators of volume to form a judgment about the relative strengths of different drinks. Participants did not tend to rank the drinks with the greatest volumes as having the highest alcohol contents. Ranking accuracy - measured as Kendall's tau for each participant was significantly predicted by the amount of alcohol a person consumed per week and by the duration over which a person had been drinking at their currently-reported frequency, albeit that the two factors explained only about $5 \%$ of the variance in the tau scores. On the other hand, gender did not predict ranking accuracy at all, and (perhaps more surprisingly) accuracy was not predicted by whether or not a person used strength information as a factor in choosing a drink.

Despite the participants' modest success in making relative judgments of strength between drinks, their estimates of the absolute strengths of individual drinks were inaccurate, both for $\% A B V$ and alcohol content in units. In terms of units, the errors were not all in a uniform direction: men and women both tended to overestimate significantly the unit contents of the spirit-based drinks but to underestimate the unit contents of most beers and wine. Women showed consistently poorer accuracy than men; worryingly, this was typically reflected in significantly greater underestimates of the numbers of units of alcohol in some of the most commonly-consumed drinks. The pattern of results for $\% A B V$ was less clear than for units; participants tended to underestimate the $\% A B V$ of those drinks for which they overestimated the unit content (and vice versa), and there was less of an apparent gender difference, indicating perhaps a widespread inability to understand and apply the 
measure meaningfully. Women tended to overestimate $\% A B V$, and their judgments were further from the actual values. The finding that people are inaccurate at estimating percentage strength information is novel.

Stockwell \& Stirling (1989) also found that adults over a wide age range were inaccurate at estimating the unit alcohol contents of drinks, tending in particular to dramatically underestimate the unit content of $13 \% \mathrm{ABV}$ wine. The present results suggest that little has changed over the subsequent decades. Hasking, Shortell, Machalek (2005) found that Australian students also had difficulties estimating the alcohol contents of standard drinks. DeVisser \& Birch (2012) asked university students to estimate the unit contents of standard measures of common alcoholic drinks, and they also found that students tended to underestimate the number of units in the drinks presented (more than $65 \%$ of judgments were underestimates). Although they did not split their (smaller, $\mathrm{N}=125$ ) sample by gender, the majority were female, consistent with our finding of a tendency for women to underestimate more than men. However, they did not look at between-drink differences, but the current data suggest that estimates vary with drink type, such that underestimates are most apparent for beers and wines. Recently, testing a convenience sample of $\mathrm{N}=283 \mathrm{UK}$ adults in a pouring task, Boniface et al. (2013) showed that the estimated unit contents of self-defined "usual" glasses of spirit and wine drinks were inaccurate by more than 0.5 units for $58 \%$ of spirit estimates and $48 \%$ of wine estimates. Overestimation of the unit contents of self-defined glasses of wine and spirits was more common than underestimation (beers were not tested), but interestingly the proportion of female underestimators was almost twice that of male underestimators, and a greater proportion of men than women were accurate; although these differences were not significant, the profile is consistent with the 
present results. Women may be less accurate because they have less experience of drinking alcohol (fewer drinking occasions and fewer drinks per occasion), reflected in their lower self-reported levels of intake. Indeed, taking the sample as a whole, there was a weak correlation between overall level of alcohol intake per week and estimation accuracy for units of alcohol for 6 of the 10 drinks, suggesting a role for drinking experience.

Congruently, White et al. (2003) reported that accuracy in pouring measures of alcohol (shots and mixed drinks, but not beers) was weakly related to drinking experience. However, we found little evidence that the frequency of consumption of specific drinks was related to accuracy in estimating drink strengths. In general, some participants' estimates were often surprisingly inaccurate even for drinks they regularly consumed. Only for one drink, the lager beer Carling, were regular drinkers significantly more accurate than occasional/never drinkers. This was not a reflection of the drink being especially popular among the sample (56\% reported at least occasional consumption, versus $85 \%$ for Smirnoff vodka). However, the sample size here would probably allow only a large effect of drink preference to be detected.

Fewer than half the respondents selected "strength" as a reason that contributed to their choice of beverage, substantially below the proportions that identified taste and cost as factors. Importantly, the figure for "strength" is also likely to include participants who deliberately choose high-strength drinks in order to become intoxicated more effectively (Jones \& Gregory, 2009). Future studies need to examine more closely how different kinds of drinker use the information available to them: for some, alcohol content information will be used to facilitate, not minimize, alcohol intoxication. To this end, choices of low-strength versus high strength should be included among response options. Participants' responses 
regarding how circumstances may affect their choice of drink according to strength (and their influences on drinking speed) suggest at least a recognition that these factors may be adjusted to control intoxication: they reported that they are less likely to drink quickly in more formal settings (such as out for dinner with parents) or before activities requiring attention (such as a lecture or going to work). The majority of participants reported that they would choose a standard-strength drink over a stronger drink when out for dinner with their parents or when out for a quiet drink with lectures the next day. This conflicts somewhat with the claim by a majority of participants that they do not consider drink strength when choosing a drink, indicating that the phrasing and context of the question influences their self-reported sensitivity to this factor. The addition of a low-strength drink option for both questions would be helpful in future studies. Obviously, answers to these questions will also have been influenced by social conformity and social norms; drink preferences are also likely to constrain response options. Hence these responses only indicate an awareness of how such variables might be manipulated to fit particular circumstances - they do not show that such behaviours are adopted.

The key findings were that young social drinkers have a poor awareness of the actual alcohol contents of different drinks (despite unit labeling and other sources of public health information in the UK), although they can make judgments of relative strength by comparing drinks of varying volumes and percentages ABV. In general, women are less accurate than men in judging the absolute alcohol contents of drinks (although their judgments of relative strengths are no worse), and more experienced drinkers show a small advantage in accuracy over less experienced drinkers; wines and beers create more difficulties than spirit-based drinks. Most young people in the sample did not claim to 
consider drink strength as an important factor in drink choice, but they demonstrated an awareness of how it might be taken into account in particular drinking contexts. Overall, the findings might be taken as evidence of a need to provide better information to young people about the alcohol contents of drinks.

\section{REFERENCES}

Bewick, B.M., Mulhern, B., Barkham ,M., Trusler. K., Hill, A., \& Stiles, W.B. (2008). Changes in undergraduate student alcohol consumption as they progress through university. BMC Public Health, 8, 163-170.

Boniface, S., Kneale, J., \& Shelton, N. (2013). Actual and perceived units of alcohol in a selfdefined usual glass of alcoholic drinks in England. Alcoholism: Clinical and Experimental Research, 37, 978-983.

Craigs, C.L., Bewick, B.M., Gill, J., O’Maya, F., \& Radley, D. (2012). UK student alcohol consumption: A cluster analysis of drinking behaviour typologies. Health Education Journal, 71, 516-526.

Das, A.K., Corrado, O.J., Kyerematen, E., Smithson, J.A.J., \& West, R.M. (2009). Do doctors understand alcohol units? Clinical Medicine, 9, 525-527. 
Dawson, D.A., Grant, B.F., Stinson, F.S., \& Chou, P.S. (2004). Another look at heavy episodic drinking and alcohol use among college and non college youths. Journal of Studies on Alcohol, 65, 477-489.

De Visser, R.O., \& Birch, J.D. (2012). My cup runneth over: Young people's lack of knowledge of low-risk drinking guidelines. Drug and Alcohol Review, 31, SI, 206-212

DiLoreto, J.T., Siegel, M., Hinchey, D., Valerio, H., Kinzel, K., Lee, S., Chen, K., Shoaff, J.R., Kenney, J., Jernigan, D.H., \& DeJong, W. (2012). Assessment of the average price and ethanol content of alcoholic beverages by brand - United States, 2011. Alcoholism-Clinical and Experimental Research, 36, 1288-1297.

Dufour, M. C. (1999). What is moderate drinking? Defining "drinks" and drinking levels. Alcohol Research \& Health, 23, 5-14.

Fadardi, J.S., \& Cox, W.M. (2008). Alcohol-attentional bias and motivational structure as independent predictors of social drinkers' alcohol consumption Drug and Alcohol Dependence, 97, 247-256.

Ferner, R. E. \& Chambers, J. (2001). Alcohol intake: measure for measure - It hard to calculate how much you are drinking - but you should know. British Medical Journal, 323, $1439-1440$. 
Furtwaengler, N.A. \& de Visser, R.O. (2013) Lack of international consensus in low-risk drinking guidelines. Drug and Alcohol Review, 32, 11-8.

Gill, J. S. \& Donaghy, M. (2004). Variation in the alcohol content of a 'drink' of wine and spirit poured by a sample of the Scottish population. Health Education Research, 19, 485491.

Gill, J. S., Donaghy, M., Guise, J., \& Warner, P. (2007). Descriptors and accounts of alcohol consumption: methodological issues piloted with female undergraduate drinkers in Scotland. Health Education Research, 22, 27-36.

Gill, J., \& O'May, F. (2007a). How 'sensible' is the UK Sensible Drinking message? Preliminary findings amongst newly matriculated female university students in Scotland. Journal of Public Health, 29, 13-16.

Gill, J. \& O'May, F. (2007b). Practical demonstration of personal daily consumption limits: A useful intervention tool to promote responsible drinking among UK adults? Alcohol and Alcoholism, 42, 436-441.

Hasking, P., Shortell, C., \& Machalek, M. (2005). University students' knowledge of alcoholic drinks and their perception of alcohol-related harm. Journal of Drug Education, 35, 95-109. 
Heather, N., Partington, S., Partington, E., Longstaff, F., Allsop, S., Jankowski, M., Wareham, H., \& St Clair Gibson, A. (2011). Alcohol Use Disorders and Hazardous Drinking among Undergraduates at English Universities. Alcohol and Alcoholism, 46, 270-277.

Higgs, S., Stafford, L.D., Attwood, A.S., Walker, S.C., \& Terry, P. (2008). Cues that signal the alcohol content of a beverage and their effectiveness at altering drinking rates in young social drinkers. Alcohol and Alcoholism, 43, 630-635.

Jones, S.C., \& Gregory, P. (2009). The impact of more visible standard drink labelling on youth alcohol consumption: helping young people drink (ir)responsibly? Drug and Alcohol Review, 28, 230-4.

Karam, E., Kypri, K., \& Salamoun, M. (2007). Alcohol use among college students: an international perspective. Current Opinion in Psychiatry, 20, 213-221.

Kerr, W. C., Greenfield, T. K., Tujague, J., \& Brown, S. E. (2005). A drink is a drink? Variation in the amount of alcohol contained in beer, wine and spirits drinks in a US methodological sample. Alcoholism-Clinical and Experimental Research, 29, 2015-2021.

Kerr, W.C. \& Stockwell, T. (2012). Understanding standard drinks and drinking guidelines. Drug and Alcohol Review, 31, 200-205.

Kypri, K., Cronin, M., \& Wright, C. (2005). Do university students drink more hazardously than their non-student peers? Addiction, 100, 713-714. 
Office for National Statistics (2010) Drinking: Adults behaviour and knowledge in 2010. Opinions Survey Report Number 42, ONS.

Sastre, M. T. M., Mullet, E., \& Sorum, P. C. (2000). Self-assessment of inebriation from external indices. Addictive Behaviors, 25, 663-681.

Stockwell T. (1993). Influencing the labelling of alcoholic beverage containers: informing the public. Addiction, 88 (Supp/1), 53S-60S.

Stockwell, T., \& Stirling, L. (1989). Estimating Alcohol Content of Drinks - Common Errors in Applying the Unit System. British Medical Journal, 298, 571-572.

Wansink, B., \& van Ittersum, K. (2003). Bottoms up! The influence of elongation on pouring and consumption volume. Journal of Consumer Research, 30, 455-463.

Webster-Harrison, P. J., Barton, A. G., Sanders, H. P., Anderson, S. D., \& Dobbs, F. (2002). Alcohol awareness and unit labelling. Journal of Public Health Medicine, 24, 332-333.

White, A. M., Kraus, C. L., Flom, J. D., Kestenbaum, L. A., Mitchell, J. R., Shah, K. et al. (2005). College students lack knowledge of standard drink volumes: Implications for definitions of risky drinking based on survey data. Alcoholism-Clinical and Experimental Research, 29, 631638. 
White, A. M., Kraus, C. L., McCracken, L. A., \& Swartzwelder, H. S. (2003). Do college students drink more than they think? Use of a free-pour paradigm to determine how college students define standard drinks. Alcoholism-Clinical and Experimental Research, 27, 17501756. 
Table 1: Estimated rankings of the ten drinks (for $n=207$ ) in terms of total alcohol content (total number of units of alcohol) and the actual rank ordering of the drinks. Lower ranks correspond to higher alcohol content. One shot $=$ a single $25 \mathrm{ml}$ measure .

\begin{tabular}{|c|c|c|}
\hline Drink & $\begin{array}{l}\text { Mean estimated rank } \\
\text { (SD in parentheses) }\end{array}$ & Actual Rank \\
\hline 2 double Jack Daniels whiskeys & $3.2(2.9)$ & 5 \\
\hline 1 bottle Kumala white wine & $3.5(2.5)$ & 1 \\
\hline 3 pints Carling lager beer & $4.6(2.3)$ & 3 \\
\hline 1 double Smirnoff vodka & $5.0(2.3)$ & 7 \\
\hline 2 cans of Carlsberg Special Brew lager beer & $5.2(2.3)$ & 2 \\
\hline 3 bottles of Reef vodka-based "alcopop" & $5.3(2.0)$ & 4 \\
\hline 1 shot Aftershock flavoured liqueur & $6.1(2.8)$ & 9 \\
\hline 1 pint Stella Artois lager beer & $7.3(2.3)$ & 6 \\
\hline 1 shot Sourz flavoured liqueur & $7.4(2.7)$ & 10 \\
\hline 1 bottle Corona beer & $7.6(2.7)$ & 8 \\
\hline
\end{tabular}


Table 2: Results of hierarchical regression to assess the relationship between individual ranking accuracies for the strengths of 10 drinks (calculated as Kendall's tau for each participant) and drinking variables (step 1: alcohol units consumed per week; duration of drinking at frequency reported; self-reported use of strength as a factor in drinking) and gender (step 2). $\mathrm{N}=207$ respondents.

\begin{tabular}{|c|c|c|c|}
\hline & B & S.E. B & $\beta$ \\
\hline \multicolumn{4}{|l|}{ Step 1} \\
\hline Constant & .125 & .058 & \\
\hline Alcohol units consumed per week & .004 & .002 & $.180^{*}$ \\
\hline Duration of drinking at reported frequency (months) & .002 & .001 & $.142^{*}$ \\
\hline Does/does not use strength information to choose & .031 & .052 & .042 \\
\hline \multicolumn{4}{|l|}{ Step 2} \\
\hline Constant & .117 & & \\
\hline Alcohol units consumed per week & .004 & .059 & $.156^{*}$ \\
\hline Duration of drinking at reported frequency (months) & .002 & .002 & .138 \\
\hline Does/does not use strength information to choose & .033 & .001 & .044 \\
\hline Gender (female or male) & .044 & .052 & .060 \\
\hline
\end{tabular}

Note: $\mathrm{R}^{2}=.048$ for Step $1, \Delta \mathrm{R}^{2}=.003$ for Step $2(\mathrm{p}<0.05) .{ }^{*} \mathrm{p}<0.05$. 
Table 3: Participants' estimates of the numbers of units of alcohol in each of the ten drinks compared with the actual unit content of the drinks (for $n=206 / 207$ ).

\begin{tabular}{|c|c|c|c|c|c|}
\hline Drink & $\begin{array}{c}\text { Actual } \\
\text { unit } \\
\text { content }\end{array}$ & $\begin{array}{c}\text { Mean } \\
\text { estimate } \\
\text { (SD) }\end{array}$ & t-value & df & p-value \\
\hline \multicolumn{6}{|l|}{ Underestimated number of units } \\
\hline 1 bottle Kumala white wine* & 9.8 & $6.2(3.5)$ & -15.2 & 205 & $<0.0025$ \\
\hline 3 pints Carling lager beer* & 7.0 & $4.9(2.1)$ & -14.6 & 206 & $<0.0025$ \\
\hline 2 cans Carlsberg Special Brew lager beer* & 9.0 & $4.5(3.2)$ & -20.2 & 206 & $<0.0025$ \\
\hline 1 pint Stella Artois lager beer* & 3.0 & $2.3(1.8)$ & -5.5 & 205 & $<0.0025$ \\
\hline \multicolumn{6}{|l|}{ Overestimated number of units } \\
\hline 2 double Jack Daniels whiskeys* & 4.0 & $5.6(4.9)$ & 4.7 & 205 & $<0.0025$ \\
\hline 1 double Smirnoff vodka* & 1.9 & $3.6(3.9)$ & 6.2 & 206 & $<0.0025$ \\
\hline 1 shot Sourz flavoured liqueur* & 0.4 & $2.2(2.5)$ & 10.3 & 206 & $<0.0025$ \\
\hline 1 shot Aftershock flavoured liqueur* & 1.0 & $2.6(3.5)$ & 6.5 & 206 & $<0.0025$ \\
\hline 1 bottle Corona beer* & 1.5 & $2.5(3.1)$ & 4.8 & 205 & $<0.0025$ \\
\hline 3 bottles Reef vodka-based "alcopop" & 4.1 & $4.2(2.2)$ & 0.9 & 206 & 0.386 \\
\hline
\end{tabular}

* indicates a significant difference between participants' estimates and actual values 
Table 4: Participants' estimates of the alcohol strengths of the ten drinks in terms of their percentage alcohol-by-volume (\% ABV) compared with the actual \%ABV values of the drinks (for $n=204 / 205)$.

\begin{tabular}{|c|c|c|c|c|c|}
\hline Drink & $\begin{array}{l}\text { Actual } \\
\text { \%ABV }\end{array}$ & $\begin{array}{c}\text { Mean } \\
\text { estimate } \\
\text { (SD) }\end{array}$ & t-value & df & p-value \\
\hline \multicolumn{6}{|l|}{ Underestimated measure of \%ABV } \\
\hline 2 double Jack Daniels whiskey* & 40.0 & $35.3(18.5)$ & -3.6 & 203 & $<0.0025$ \\
\hline 1 double Smirnoff vodka* & 37.5 & $30.7(17.9)$ & -5.5 & 204 & $<0.0025$ \\
\hline 1 shot Aftershock flavoured liqueur* & 40.0 & $26.3(16.1)$ & -12.2 & 204 & $<0.0025$ \\
\hline \multicolumn{6}{|l|}{ Overestimated measure of \%ABV } \\
\hline 3 pints Carling lager beer* & 4.1 & $10.4(10.5)$ & 8.6 & 203 & $<0.0025$ \\
\hline 1 shot Sourz flavoured liqueur* & 15.0 & $20.0(14.3)$ & 5.0 & 203 & $<0.0025$ \\
\hline 1 bottle Corona beer* & 4.6 & $8.0(8.4)$ & 5.8 & 204 & $<0.0025$ \\
\hline 3 bottles Reef vodka-based "alcopop"* & 5.0 & $10.2(10.3)$ & 7.3 & 204 & $<0.0025$ \\
\hline 1 pint Stella Artois lager beer* & 5.2 & $7.5(6.9)$ & 4.9 & 204 & $<0.0025$ \\
\hline 2 cans Carlsberg Special Brew lager beer & 9.0 & $11.0(10.3)$ & 2.8 & 204 & 0.005 \\
\hline 1 bottle Kumala white wine & 13.0 & $14.5(10.2)$ & 2.1 & 203 & 0.035 \\
\hline
\end{tabular}

* indicates a significant difference between participants' estimates and actual values. 
Table 5: Self-reported influence of situation on choice of drink in terms of its alcoholic strength: percentages of participants $(n=205 / 206)$ for each of 6 different situations. The options to choose were: "Stronger drink", "Standard drink", or "Would not consider drink strength at all".

\begin{tabular}{lcccccc}
\hline $\begin{array}{l}\text { Drink } \\
\text { strength }\end{array}$ & Quiet drink & $\begin{array}{c}\text { Getting } \\
\text { ready to } \\
\text { go out }\end{array}$ & Clubbing & $\begin{array}{c}\text { Pub before } \\
\text { lecture }\end{array}$ & $\begin{array}{c}\text { Dinner with } \\
\text { parents }\end{array}$ & House party \\
\hline Stronger & $2.4 \%$ & $57.3 \%$ & $65.4 \%$ & $1.9 \%$ & $2.9 \%$ & $57.8 \%$ \\
Standard & $72.8 \%$ & $30.1 \%$ & $23.4 \%$ & $47.6 \%$ & $71.4 \%$ & $28.2 \%$ \\
$\begin{array}{l}\text { Not } \\
\text { considered }\end{array}$ & $24.8 \%$ & $12.6 \%$ & $11.2 \%$ & $50.5 \%$ & $25.7 \%$ & $14.1 \%$ \\
\hline
\end{tabular}


Figure 1: The numbers of participants who reported ever selecting alcoholic beverages on the basis of any of five different factors $(n=207)$

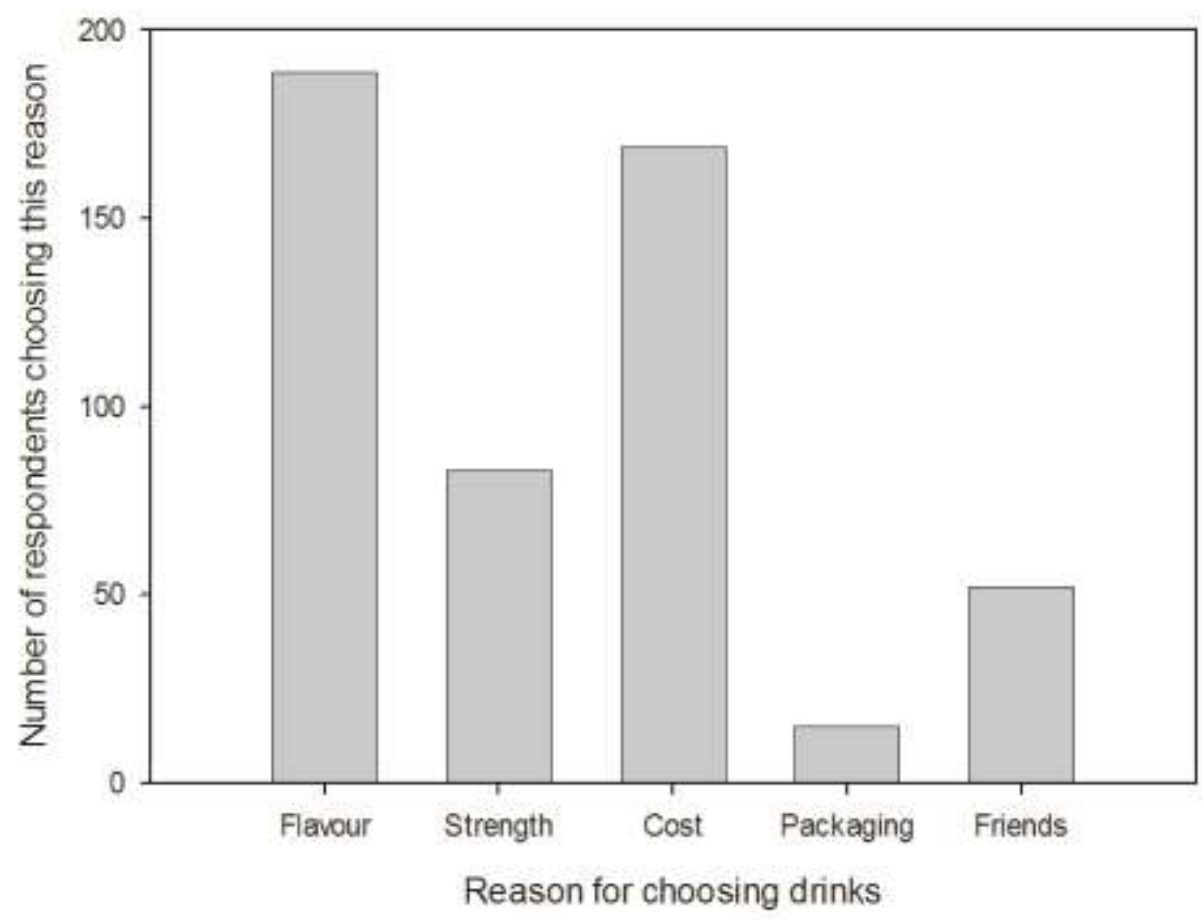

